\title{
Commitment to Emissions Restrictions of Major Consumers of Electricity in Brazil
}

Fabricio Casarejos ${ }^{1,2, *}$, Mauricio Nogueira Frota ${ }^{1, \dagger, *}$, Gil Penha-Lopes ${ }^{2, \dagger}$, Vagner Viana Silva ${ }^{1, \dagger}$ and Fernanda Particelli ${ }^{3, \dagger}$

1 Postgraduate Program in Metrology for Quality and Innovation, Catholic University of Rio de Janeiro, Rua Marquês de São Vicente, 225-Gávea, Rio de Janeiro-RJ 22453-900, Brazil; E-Mail: silvaufrrj@gmail.com

2 Climate Change Impacts, Adaptation \& Modeling Research Group (CCIAM), Center for Ecology, Evolution and Environmental Changes (CE3C), Faculty of Sciences, Lisbon University, Lisboa 1749-016, Portugal; E-Mail: gppenha-lopes@fc.ul.pt

3 Light Serviços de Eletricidade S/A, Marechal Floriano, Rio de Janeiro-RJ 20080-002, Brazil; E-Mail: fernanda.particelli@light.com.br

$\dagger$ These authors contributed equally to this work.

* Author to whom correspondence should be addressed; E-Mails: casarejos@fc.ul.pt (F.C.); mfrota@puc-rio.br (M.N.F.); Tel.: +55-21-3527-1171 (M.N.F.); Fax: +55-21-3527-2060 (M.N.F.).

Received: 24 June 2014; in revised form: 28 August 2014 / Accepted: 26 August 2014 /

Published: 15 September 2014

\begin{abstract}
In the context of global concerns about climate change that stem from the alarming and unprecedented growth of greenhouse gas (GHG) emissions, this study discusses the use of energy by large consumers of electricity in Brazil in the perspective of sustainable development, energy resources, and regulatory policies. It evaluates the commitment to emissions restrictions among the major customers of an electricity utility company that serves 4.1 million consumers $(68 \%$ of the population and $66 \%$ of the gross internal product for the second-highest economically developed Brazilian state). The evaluation is based on proposed metrics and indicators. By considering the Brazilian commitment to a policy of sustainable development, this study reviews the primary international agreements and recommendations that have been developed to mitigate and adapt to climate change and sustainability. A survey was developed for participating organizations classified by economic sector to assess their awareness to 18 issues that reflect international guidelines on emission constraints. Based on total energy consumption,
\end{abstract}


the survey discusses the worrying level of GHG emissions $\left(\mathrm{tCO}_{2} \mathrm{eq}\right)$ that is associated with the generation of electricity by customers of the largest utility company. In spite of $90 \%$ of the organizations having considered sustainability as a business opportunity and a competitive differential that enables niche markets, the results of this study demonstrated low commitment to the desired emissions restrictions.

Keywords: climate change; sustainable development; public policy; global warming; greenhouse gas emissions

\section{Introduction}

The search for sustainable developmental models and effective adaptation and mitigation strategies for climate change is a recurring challenge for contemporary societies [1-4]. Scientific evidence of climate change due to the emission of greenhouse gases (GHG) by human activities began to cause public concern in the 1980s [5]. After the creation of the Intergovernmental Panel on Climate Change (IPCC) in 1998, this issue gained international exposure and was considered to be an actual threat [6,7]. To stimulate the debate on critical subjects related to sustainable development and climate change, a schedule of international conferences and a set of actions were proposed by the United Nations and the United Nations Framework Convention on Climate Change (UNFCCC) [5,6,8].

The current consensus on climate change was published in the 4th Assessment Report of the IPCC almost one decade after its creation [2] (IPCC, 2007). The report revealed that the effect of human activities since 1750 produced $+1.6(+0.6$ to +2.4$) \mathrm{Wm}^{-2}$, with an increase of $0.2{ }^{\circ} \mathrm{C}$ per decade in the environmental temperature over the last few years. These data form the fundamental basis of the assessment that the planet is unavoidably subject to a (threatening) "global warming" process induced by the high concentration of GHGs in the atmosphere [2,3]. Official IPCC data indicated that global emission levels increased from $280 \mathrm{ppm}$ to $379 \mathrm{ppm}$ in 2005 and attained a level of $391 \mathrm{ppm}$ in $2011[2,4]$. These levels are significantly higher than the levels recorded prior to the industrial revolution. Recent research indicates that climate change will intensify in the future and cause structural transformations that will exert long-term effects on the global economy and quality of life, potentially threatening all nations [4,9-11].

Climate change has emerged as an externality with high risks to economies and business cycles [12-14]. Issues associated with climate change and sustainability have influenced the decisions of both governmental and nongovernmental leaders and the behaviors and relationships of civil society [4,14-18]. The development of a regulatory framework, the engagement of public opinions on sustainability, the expansion of an ethical and conscious consumption culture, the knowledge of sustainable management techniques and the establishment of financial governmental incentives have pressured organizations to incorporate climate change into their strategic visions [14,19-21]. 


\section{National Policy on Climate Change and GHG Emissions}

Due to its commitment to sustainable development, Brazil has played an important role in the creation of international mechanisms and agreements that address the challenges of climate change. The following accomplishments highlight the primary actions and experiences that characterize Brazil's position on global climate policy:

- Served as the headquarters for two of four UN conferences on sustainability, sustainable development and climate change [22,23];

- Achieved a position of leadership in the reduction of GHG emissions in deforestation and land use, which are referred to as land use, land use change and forestry (LULUCF1) emissions [24,25];

- Accumulated extensive experience with hydroelectric power generation and bio-fuels, which prompted the conception of the clean development mechanisms (CDMs) of the Kyoto Protocol;

- Promulgated, in December 2009, its National Policy on Climate Change (NPCC), which was established as Law 12187/2009;

- Committed (voluntarily) to reducing GHG emissions to a level between $36.1 \%$ and $38.9 \%$ to satisfy the international levels (COP-16/Cancun) for 2020 (Art. 12 of Law 12187/2009) [26], which defines the mandatory publishing of annual governmental reports on the emission of GHGs, beginning in 2012, in a manner that can be understood by any interested segments of society.

The Brazilian Climate Change Policy is a relevant framework that integrates and harmonizes public policies that address the challenges induced by sustainability and climate change. This framework aims to encourage the development and improvement of sectoral actions towards sustainability and climate change mitigation and adaptation strategies. It collaborates with the global effort to reduce GHG emissions and initiatives to create internal conditions for managing the impacts of global climate change. Although Brazil is a signatory of the Framework Convention, it did not formally commit to reducing its GHG emissions, as did the countries listed in Annex I of the UNFCCC. However, Brazil elaborates GHG emission inventories; formulates national programs of mitigation and adaptation to climate change; promotes technological, scientific and educational cooperation in sustainability and climate change and promotes the sustainable management of carbon sinks and reservoirs.

According to the most recent Brazilian Energy Balance [25], 42.4\% of the Brazilian energy matrix, which comprises a total of $592.8 \mathrm{TWh}$, consists of renewable sources (hydroelectric, $76.8 \%$; biomass, 6.8\%; natural gas, $7.9 \%$; nuclear, $2.7 \%$; petroleum products, $3.3 \%$; coal and its products, $1.6 \%$; and wind, $0.9 \%$ ). The GHG emissions associated with this energy matrix total $430 \mathrm{MtCO}_{2} \mathrm{eq}$, of which $48.8 \%$ (210 $\left.\mathrm{MtCO}_{2} \mathrm{eq}\right)$ are produced by the transportation sector. According to the official data from the Brazilian government [25,27], the per-capita GHG emissions in Brazil is $2 \mathrm{tCO}_{2} \mathrm{eq}$, which is significantly less than the per-capita emissions of the USA $\left(17 \mathrm{tCO}_{2} \mathrm{eq}\right)$, the per-capita emissions of the European Union countries ( $\left.7 \mathrm{tCO}_{2} \mathrm{eq}\right)$ and the per-capita emissions of China ( $\left.5 \mathrm{tCO}_{2} \mathrm{eq}\right)$. The carbon intensity of the Brazilian economy was approximately $0.2 \mathrm{~kg} \mathrm{CO} 2 \mathrm{eq} / \mathrm{US} \$$ in 2011 , which indicates that the Brazilian economy is less carbon-intensive than other economies. The carbon intensity of the Brazilian economy is two times less than the carbon intensity of the American economy, 1.4 times less than the carbon intensity of the European economy and 2.8 times less than the carbon intensity of the 
Chinese economy. For each MWh generated in 2012, the Brazilian power industry emitted an average of $82 \mathrm{~kg}$ of $\mathrm{CO}_{2}$ eq [24,25].

Although Brazil reduced its GHG emissions by $1 \%$ - from $112.8 \mathrm{GtCO}_{2} \mathrm{eq}(2010)$ to $111.6 \mathrm{GtCO}_{2} \mathrm{eq}$ (2011) - via a program to reduce deforestation and increase the awareness of land and forest use, a significant increase in the share of emissions from industrial activities (which increased from $4 \%$ of the total emissions in 2005 to $7 \%$ of the total emissions in 2010) and electric power [28] generation and use (which increased from $16 \%$ of the total emissions to $32 \%$ of the total emissions for the same period) is evident. That is, the combined share of emissions from these sectors of the Brazilian economy increased from $20 \%$ of the total emissions to $39 \%$ of the total emissions between 2005 and 2010 .

\section{Theoretical Background: Climate Change Actions and Strategies}

The impacts and consequences of climate change challenge managers, policy makers and organizations, as climate change can potentially threaten business environments; affect lifestyles, values and social practices; and create environmental conflicts [14,27,29]. Amongst the numerous causes of climate change, the consumerism of urban lifestyles, the fragmentation of ecosystemic resources and services, intense energy usage and high GHG emissions are notable [4,30]. Government and nongovernment leaders must have the perspicacity to scientifically understand the complexity of these processes and overcome these challenges to prevent collateral damage caused by emergency remediation [4,19,31]. To adequately address these challenges, which are not always predictable, organizations may benefit by adopting new adaptation and mitigation strategies for growth and development. These strategies include the utilization of reduced GHG emissions in an organization's maintenance and growth; the re-evaluation of values, policies and management models; the development of new products, services and markets; the adoption of new modes of productivity, competitiveness and relationships; the diagnosis of risks and emerging opportunities; the formulation of conscious norms and policies and the anticipation and adaptation to new realities to enable the future use of preventive and control measures [13,14,19,31-34].

The challenge of formulating effective GHG and sustainability management strategies is to understand the current actions and intentions of an organization. Each organization constitutes a unique universe with distinct social, economic, environmental and institutional specificities [12]. The development of policies and strategies that are specific to an organization requires knowledge based on scientific concepts and reliable data. Policy analysis and evaluation require a detailed diagnosis of the performed activities and an understanding of the specificities. Since the implementation of the Kyoto Protocol in 1997 [35], many organizations have considered sustainability and climate change strategies as business strategies [14,19,33,34,36,37].

The following scientific studies on corporate sustainability and climate change strategies are highlighted: "corporate environmentalism" [12], "climate change strategy" [38], "climate strategy" [39], "corporate strategies" [12], "carbon strategies" [40], "the business response to climate change" [41], "the corporate $\mathrm{CO}_{2}$ strategy" (Weinhofer and Hoffmann, 2010), and "corporate carbon strategy" [37]. These studies indicate a competitive advantage for organizations that are capable of incorporating climate change into their strategic planning, which ensures improved conditions for the exploitation of opportunities that emerge from a changing business environment. The studies also reinforce the idea 
that climate change strategies must be integrated into an organization's priority strategies. Climate change and sustainability business strategies are expressed as goals and execution plans, which are intended to reduce GHG emissions and benefit society.

Various studies and reports discussed in international forums [3,5,6,11,22,23,27,29,31] have proven that government entities have attempted to establish considerations and judgements for mitigating and adapting to the challenges of climate change and sustainability. These changes correspond with the societal need for a transition to a low-carbon economy and technically feasible, financially feasible and pragmatic solutions for reducing GHG emissions, which can be implemented for sustainable development [5-7].

To guide the development of this study, a set of 14 critical actions related to climate change and sustainability were identified. These corporate strategic actions, which were formulated based on the studies and reference documents discussed in this study, are listed as follows:

(1) Implement a specific and/or specialized section or department to develop projects, programmes and management models;

(2) Promote the discussion of these issues with the organization's board of directors;

(3) Obtain a commitment from the organization's top management team to reduce and compensate for GHG emissions;

(4) Perform GHG emission inventories;

(5) Promote the publication of GHG emission inventory reports;

(6) Promote the development and utilization of financial mechanisms for climate change and sustainability initiatives;

(7) Develop CDM projects and participate in domestic and international carbon markets;

(8) Perform short-, medium-, and long-term risk and opportunity analyses in the context of climate change and sustainability agendas;

(9) Adjust to emergent norms and policies due to climate change and sustainability agendas;

(10) Promote the development of new businesses and competitiveness strategies;

(11) Establish activities that reflect acceptable practices in the business environment;

(12) Promote the development of efficient processes and "green" products;

(13) Ensure the involvement of stakeholders on issues related to climate change and sustainability;

(14)Develop a participative, communicative and transparent relationship with stakeholders and shareholders.

These critical actions for corporate climate change and sustainability strategies comprise the foundation for constructing the data collection instrument used for the case study.

\section{Objective}

The objective of this study is to identify and analyze the actions and degrees of commitment to emissions restrictions by the high-consuming customers [42] of an electric utility in Brazil, which can be used to address the challenges of sustainability and climate change. 


\section{Methodology}

The study "Research in sustainability: actions and commitment of large customers of an electricity utility company" consisted of the following 4 phases:

- Scope definition-Diagnosis of the actions and degrees of commitment of customers of an electric utility in Brazil based on globally condensed guidelines, which were summarized by the 14 critical actions.

- Definition of the research universe and sample - of the 4674 high-consuming customers of the Brazilian electricity power company "Light Serviços de Eletricidade S/A", 162 customers that effectively participate in the strategic business cycles promoted by the utility agreed to participate in this study. The organization's selection considered the following criteria: (i) medium- and high-voltage energy consumption [43]; (ii) the availability of an updated register; (iii) participation by a manager who is knowledgeable about the issues of climate change and sustainability; and (iv) voluntary participation in the study. Of the 162 customers, $86(53 \%)$ customers responded to the survey; they constitute the research sample, which was structured by the industrial classifications provided by the utility and the Brazilian Institute of Geography and Statistics (Instituto Brasileiro de Geografia e Estatística). The sample was composed of the following organizations: 32 Manufacturing Industry companies (mining companies, construction companies and factories), 28 Commerce companies (supermarket chains, shopping centers, gas stations and service providers); nine Public Organizations (government agencies, banks, hospitals, nongovernmental organizations (NGOs) and transportation companies), seven Education and Research entities (universities, R\&D centers and professional training centers), and 10 Tourism, entertainment and culture companies (large leisure centers, hotels and radio and television networks).

- Conception of the data collection instrument - Given the characteristics of the opinion surveys, the authors opted for a structured questionnaire composed of 11 central questions (closed and nonobligatory), which were carefully designed to reflect adherence to the rules and recommendations of international studies and guidelines and the 14 critical actions prioritized in Section 3. The adherence of these questions to the critical actions and content is reflected in the aggregate summary of answers, which is shown in Table 1. The 11 central questions contain 13 subquestions, of which eight are include [YES] answers and five include [NO] answers. Generally, the questionnaire contains 18 [YES] or [NO] answers and 48 multiple-choice questions.

- Application of the questionnaire-Prior to distributing the survey questionnaire to the participants, an awareness letter (co-signed by the university responsible for this study and the electricity utility) was sent to the managements of the participating entities to explain the survey context and to request participation by a manager who is knowledgeable of the entity's actions regarding climate change and sustainability. After this step, which ensured the respondent's familiarity with the scope of the survey, the questionnaire was distributed via an online digital tool. The questionnaire was available to the respondents during a 60-day period (July-August 2013), and the survey coordinator interacted with each respondent via telephone and e-mail. 
The analysis of the survey results established the basis for (i) the development of an indicator of the degree of a participant's commitment and adherence to the critical actions prioritized in Section 3, (ii) the construction of metrics to measure the proposed indicator, (iii) the calculation of GHG emissions $\left(\mathrm{CO}_{2} \mathrm{eq}\right)$ from the generation of the electrical energy consumed by the organizations examined in this study and (iv) a comparison of the degree of commitment and GHG emissions for each sampled section.

\section{Results and Discussion}

The aggregated results of the survey are shown in Tables 1 and 2, which summarise the answers in both absolute (total respondents) and percentage terms. Table 1 displays the 11 central questions, corresponding to 13 subquestions with answer options, the critical actions associated with each question and the tabulated results. Table 2 displays the six subquestions with multiple answering options (a total of 48 questions), the critical actions and the results. In the subsequent section, each result is discussed as it relates to international studies and guidelines on sustainability and strategies to mitigate and adapt to climate change.

Table 1. Answers to the 11 questions of the questionnaire and corresponding sub questions.

\begin{tabular}{|c|c|c|c|c|c|c|c|c|}
\hline \multirow[t]{2}{*}{ Question \# } & \multirow[t]{2}{*}{$\begin{array}{l}\text { Reference to } \\
\text { Critical } \\
\text { Actions }\end{array}$} & \multirow[t]{2}{*}{$\begin{array}{l}\text { Survey questions ["Study in sustainability: } \\
\text { Actions and commitment of large customers of a } \\
\text { power utility company"] }\end{array}$} & \multicolumn{2}{|c|}{$\begin{array}{l}\text { Total } \\
\text { Answers }\end{array}$} & \multicolumn{2}{|c|}{$\begin{array}{l}\text { Affirmative } \\
\text { Answers } \\
\text { [YES] }\end{array}$} & \multicolumn{2}{|c|}{$\begin{array}{l}\text { Negative } \\
\text { Answers } \\
\text { [NO] }\end{array}$} \\
\hline & & & \# & $(\%)$ & \# & $(\%)$ & \# & $(\%)$ \\
\hline Question \#1 & \# 1 and 2 & $\begin{array}{l}\text { Does the organization have a specific division to } \\
\text { manage sustainability (Su) activities (projects, } \\
\text { programs) and mitigation/adaption strategies for } \\
\text { climate change (CC)? }\end{array}$ & 86 & 100.0 & 25 & 29.0 & 61 & 71.0 \\
\hline $1-[\mathrm{NO}]$ & \multicolumn{2}{|c|}{ Does the organization intend to create such a division? } & 61 & 100.0 & 15 & 24.5 & 46 & 75.5 \\
\hline $1-[\mathrm{NO}]$ & \multicolumn{2}{|c|}{$\begin{array}{l}\text { Are these issues }(\mathrm{Su}, \mathrm{CC}) \text { currently discussed by the Board of } \\
\text { Directors of the organization? }\end{array}$} & 61 & 100.0 & 8 & 13.1 & 53 & 86.9 \\
\hline Question \#2 & \# 3, & $\begin{array}{l}\text { Does the organization perform greenhouse effect } \\
\text { gas }(G G) \text { inventories? }\end{array}$ & 86 & 100.0 & 10 & 11.6 & 76 & 88.4 \\
\hline 2-[YES] & \multicolumn{2}{|c|}{ Does the Organization annually project its GG emissions? } & 10 & 100.0 & 8 & 80.0 & 2 & 20.0 \\
\hline $2-[\mathrm{NO}]$ & \multicolumn{2}{|c|}{ Does the Organization intend to create GG inventories? } & 74 & 97.4 & 20 & 27.0 & 54 & 73.0 \\
\hline Question \#3 & \# 6 & $\begin{array}{l}\text { Does the organization know about the fiscal/tax } \\
\text { benefits to stimulate the reduction of greenhouse } \\
\text { GAS emissions? }\end{array}$ & 85 & 99.0 & 21 & 24.7 & 64 & 75.3 \\
\hline $3-[\mathrm{YES}]$ & \multicolumn{8}{|c|}{$\begin{array}{l}\text { Of the listed options, indicate the fiscal/tax benefits you are aware of: } \\
\text { (see options in line 3-[YES] of Table 2) }\end{array}$} \\
\hline $3-[\mathrm{NO}]$ & \multicolumn{2}{|c|}{ Are you interested in knowing about these fiscal/tax benefits? } & 64 & 100.0 & 56 & 87.5 & 8 & 12.5 \\
\hline Question \#4 & $\# 7$ & Does the organization know of the carbon market? & 32 & 37.2 & 13 & 40.6 & 19 & 59.4 \\
\hline 4-[YES] & \multicolumn{8}{|c|}{ Indicate any of the listed options applicable (see options in line 4-[YES] of Table 2) } \\
\hline $4-[\mathrm{NO}]$ & Are you intere & ested in knowing about this market? & 19 & 100.0 & 13 & 68.4 & 6 & 31.6 \\
\hline Question \#5 & $\# 8,9$ and 10 & $\begin{array}{l}\text { Does the organization perform any periodical } \\
\text { analysis of Risks/Opportunities created to climate } \\
\text { change and sustainability? }\end{array}$ & 25 & 29.0 & 7 & 28.0 & 18 & 72.0 \\
\hline Questi & & $\begin{array}{l}\text { Does the organization perceive sustainability as a } \\
\text { business opportunity? }\end{array}$ & 84 & 97.7 & 76 & 90.5 & 8 & 9.5 \\
\hline
\end{tabular}


Table 1. Cont.

\begin{tabular}{|c|c|c|c|c|c|c|c|c|}
\hline \multirow[t]{2}{*}{ Question \# } & \multirow[t]{2}{*}{$\begin{array}{l}\text { Reference to } \\
\text { Critical } \\
\text { Actions }\end{array}$} & \multirow{2}{*}{$\begin{array}{l}\text { Survey questions [“Study in sustainability: } \\
\text { Actions and commitment of large customers of a } \\
\text { power utility company”] }\end{array}$} & \multicolumn{2}{|c|}{$\begin{array}{l}\text { Total } \\
\text { Answers }\end{array}$} & \multicolumn{2}{|c|}{$\begin{array}{l}\text { Affirmative } \\
\text { Answers } \\
\text { [YES] }\end{array}$} & \multicolumn{2}{|c|}{$\begin{array}{l}\text { Negative } \\
\text { Answers } \\
\text { [NO] }\end{array}$} \\
\hline & & & $\#$ & $(\%)$ & $\#$ & $(\%)$ & \# & $(\%)$ \\
\hline Question \#7 & $\# 10$ and 13 & $\begin{array}{l}\text { Does the organization perceive Sustainability as a } \\
\text { competitive business differential? }\end{array}$ & 86 & 100.0 & 82 & 95.4 & 4 & 4.6 \\
\hline 7-[YES] & \multicolumn{8}{|c|}{$\begin{array}{l}\text { Of the options offered, indicate which result from Sustainability strategies; } \\
\text { (see options in line 7-[YES] of Table 2) }\end{array}$} \\
\hline Question \#8 & $\# 11$ and 13 & $\begin{array}{l}\text { Does the organization develop good Sustainability } \\
\text { practices? }\end{array}$ & 86 & 100 & 86 & 100 & 0 & 0 \\
\hline 8-[YES] & $\begin{array}{l}\text { Of the options } \\
\text { (see options in }\end{array}$ & $\begin{array}{l}\text { s offered, indicate those effectively practiced: } \\
\text { n line } 8 \text {-[YES] of Table 2) }\end{array}$ & & & & & & \\
\hline Question \#9 & $\# 12$ and 13 & $\begin{array}{l}\text { Has the organization ever participated in a } \\
\text { program/competition that rewards sustainability? }\end{array}$ & 25 & 29.0 & 4 & 16.0 & 21 & 84.0 \\
\hline 9-[YES] & $\begin{array}{l}\text { In the context } \\
\text { has won any } \mathrm{p}\end{array}$ & $\begin{array}{l}\text { of this initiative, indicate whether the Organization } \\
\text { prize. }\end{array}$ & 4 & 4.6 & 4 & 100.0 & 0 & 0 \\
\hline Question \#10 & \# 9 to 13 & $\begin{array}{l}\text { Did the organization received any mark of } \\
\text { conformity or certificate in sustainability and } \\
\text { energy efficiency? }\end{array}$ & 86 & 100.0 & 13 & 15.0 & 73 & 85.0 \\
\hline 10-[YES] & $\begin{array}{l}\text { Of the listed of } \\
\text { Certificate rece }\end{array}$ & $\begin{array}{l}\text { options, indicate the mark of conformity or } \\
\text { ceived: }\end{array}$ & & & & & & \\
\hline Question \#11 & \# 5 and 14 & $\begin{array}{l}\text { Does the organizations publicize its actions } \\
\text { regarding sustainability and climate change? }\end{array}$ & 18 & 20.9 & 18 & 100 & 0 & 0 \\
\hline 11-[YES] & $\begin{array}{l}\text { Of the options } \\
\text { (see options in }\end{array}$ & $\begin{array}{l}\text { s offered, indicate the media utilized: } \\
\text { n line 11-[YES] of Table 2] }\end{array}$ & & & & & & \\
\hline
\end{tabular}

Table 2. Answers to the questionnaire (multiple options).

\begin{tabular}{|c|c|c|c|c|c|c|}
\hline \multirow{2}{*}{\multicolumn{2}{|c|}{$\begin{array}{l}\text { Unfolding of the Survey Questions } \\
\text { (Multiple Choice options) }\end{array}$}} & \multicolumn{2}{|c|}{$\begin{array}{l}\text { Total } \\
\text { Answers }\end{array}$} & \multirow[t]{2}{*}{ Alternatives of Multiple Options of Answers } & \multicolumn{2}{|c|}{$\begin{array}{l}\text { Total } \\
\text { Answers }\end{array}$} \\
\hline & & \# & $(\%)$ & & \# & $\%$ \\
\hline \multirow[b]{3}{*}{3 -[YES] } & \multirow{3}{*}{$\begin{array}{l}\text { Of the listed options, } \\
\text { indicate which fiscal/tax } \\
\text { benefits may help reduce } \\
\text { the emission of } \\
\text { greenhouse gases (GG)? }\end{array}$} & \multirow[b]{3}{*}{20} & \multirow[b]{3}{*}{95.2} & a. access to differentiated financing & 13 & 65 \\
\hline & & & & b. tax reduction & 9 & 45 \\
\hline & & & & c. eligibility for the green market - carbon market & 10 & 50 \\
\hline \multirow{3}{*}{ 4-[YES] } & \multirow{3}{*}{$\begin{array}{l}\text { Of the listed options, } \\
\text { indicate the company's } \\
\text { current participation in } \\
\text { the carbon market: }\end{array}$} & \multirow{3}{*}{7} & \multirow{3}{*}{53.8} & a. has plans to elaborate a project & 5 & 71.4 \\
\hline & & & & b. has an ongoing $\mathrm{CDM}$ project & 2 & 28.6 \\
\hline & & & & $\begin{array}{l}\text { c. has already obtained carbon credits (CERs, } \\
\text { Certificated Emissions) }\end{array}$ & 1 & 14.3 \\
\hline \multirow{5}{*}{ 7-[YES] } & \multirow{5}{*}{$\begin{array}{l}\text { Of the listed options, } \\
\text { indicate which } \\
\text { contributions result from } \\
\text { a sustainability strategy: }\end{array}$} & \multirow{5}{*}{82} & \multirow{5}{*}{100.0} & a. reduction of fixed costs & 64 & 78.8 \\
\hline & & & & b. commitment from stakeholders and shareholders & 30 & 36.6 \\
\hline & & & & c. $\quad$ strategic and operational efficiency & 54 & 65.8 \\
\hline & & & & d. preference from consumers, suppliers and investors & 54 & 65.8 \\
\hline & & & & e. development of new markets & 43 & 52.4 \\
\hline
\end{tabular}


Table 2. Cont.

\begin{tabular}{|c|c|c|c|c|c|c|}
\hline \multirow{2}{*}{\multicolumn{2}{|c|}{$\begin{array}{l}\text { Unfolding of the Survey Questions } \\
\text { (Multiple Choice options) }\end{array}$}} & \multicolumn{2}{|c|}{$\begin{array}{l}\text { Total } \\
\text { Answers } \\
\end{array}$} & \multirow[t]{2}{*}{ Alternatives of Multiple Options of Answers } & \multicolumn{2}{|c|}{$\begin{array}{l}\text { Total } \\
\text { Answers }\end{array}$} \\
\hline & & $\#$ & $(\%)$ & & $\#$ & $\%$ \\
\hline & & & & f. pioneering and anticipation & 45 & 54.8 \\
\hline & & & & g. company and product differentiation & 57 & 69.5 \\
\hline & & & & h. Branding improvement & 22 & 26.8 \\
\hline & & & & i. others & 0 & 0 \\
\hline \multirow{13}{*}{ 8-[YES] } & \multirow{13}{*}{$\begin{array}{l}\text { Of the listed options, } \\
\text { indicate which } \\
\text { sustainability activities } \\
\text { are effectively practiced } \\
\text { by the organization: }\end{array}$} & \multirow{13}{*}{86} & \multirow{13}{*}{100} & a. selective garbage collection & 69 & 80.2 \\
\hline & & & & b. sewage and wastewater treatment & 56 & 65.1 \\
\hline & & & & c. generation and/or utilization of renewable energy & 25 & 29.0 \\
\hline & & & & d. recycling and reuse of residues & 60 & 69.8 \\
\hline & & & & e. energy efficiency and raw materials optimization & 36 & 41.8 \\
\hline & & & & f. environmental education & 44 & 51.1 \\
\hline & & & & g. capture of rainwater & 28 & 32.6 \\
\hline & & & & h. reverse logistics of its products & 17 & 19.8 \\
\hline & & & & i. neutralization/compensation of carbon emissions & 12 & 14.0 \\
\hline & & & & j. $\quad$ social development programs & 43 & 50.0 \\
\hline & & & & k. cultural development programs & 31 & 36.0 \\
\hline & & & & 1. professional well-being programs & 44 & 51.1 \\
\hline & & & & m. others & 2 & 2.3 \\
\hline \multirow{9}{*}{10 -[YES] } & \multirow{9}{*}{$\begin{array}{l}\text { Of the listed options, } \\
\text { indicate the seals and } \\
\text { certificates received for } \\
\text { sustainability and energy } \\
\text { efficiency: }\end{array}$} & \multirow{9}{*}{13} & \multirow{9}{*}{15.1} & $\begin{array}{l}\text { a. AQUA (High Environmental Quality) — Alta } \\
\text { Qualidade Ambiental }\end{array}$ & 0 & 0 \\
\hline & & & & $\begin{array}{l}\text { b. LEED (Leadership in Energy \& Environmental } \\
\text { Design) }\end{array}$ & 3 & 23.0 \\
\hline & & & & $\begin{array}{l}\text { c. PROCEL Edifica (National Program of Energy } \\
\text { Conservation) - Programa Nacional de } \\
\text { Conservação de Energia }\end{array}$ & 1 & 7.7 \\
\hline & & & & d. Qualiverde & 1 & 7.7 \\
\hline & & & & e. Solar & 1 & 7.7 \\
\hline & & & & f. $\quad$ FSC (Forest Stewardship Council) & 4 & 30.8 \\
\hline & & & & g. Casa Azul Caixa & 0 & 0 \\
\hline & & & & h. ISO 14001 & 1 & 7.7 \\
\hline & & & & i. others & 0 & 0 \\
\hline \multirow{11}{*}{ 11-[YES] } & \multirow{11}{*}{$\begin{array}{l}\text { Of the options offered, } \\
\text { indicate the media utilized } \\
\text { by the organization to } \\
\text { publicize its sustainability } \\
\text { and climate change } \\
\text { activities: }\end{array}$} & \multirow{11}{*}{18} & \multirow{11}{*}{20.9} & a. sustainability report & 7 & 38.9 \\
\hline & & & & b. "Carbon Disclosure Project" (CDP) report & 0 & 0 \\
\hline & & & & c. corporate social responsibility report & 0 & 0 \\
\hline & & & & d. corporate annual report & 8 & 44.4 \\
\hline & & & & e. GHG emissions public registration (GHG Protocol) & 1 & 5.5 \\
\hline & & & & f. radio & 1 & 5.5 \\
\hline & & & & g. television & 1 & 5.5 \\
\hline & & & & h. $\quad$ specialized journals & 4 & 22.2 \\
\hline & & & & i. journalistic and commercial magazines & 4 & 22.2 \\
\hline & & & & j. internet & 8 & 44.5 \\
\hline & & & & k. others & 2 & 11.1 \\
\hline
\end{tabular}




\subsection{Question-by-Question Analysis of the Answers}

Question \#1: Only $29 \%$ of the survey respondents indicated the presence of a specific division in their organization for addressing climate change and sustainability issues; $25 \%$ of the respondents indicated plans to implement such a section. Only $47 \%$ of the respondents had implemented or intended to implement such a division. The boards of directors of $13 \%$ of the organisations had discussed climate change. These results reinforce the thesis that the challenges imposed on markets, public policies and the environment by climate change and sustainability are complex and emergent $[12,14,19,27]$. The development of business strategies to respond to the challenges imposed on organizations and markets by climate change requires ample multi-disciplinary knowledge and the awareness and commitment by managers $[20,39,44]$. Organizations that implemented a specific sector to develop climate projects, programs and management models discovered that the initiative facilitated the integration of actions related to climate change and sustainability, which contributed to decision-making processes [45]. Question \#1 reflects the conclusions of the recent Global Corporate Sustainability Report [46], which was published by the United Nations after gathering the opinions of 1712 organizations across 113 countries. The report indicates that $46 \%$ of the sampled organizations incorporate sustainability into their relevant corporate functions, $90 \%$ of the sampled organizations regularly discuss sustainability as an agenda and $65 \%$ of the policy or strategy evaluations for sustainability are performed by the organization's chief executive officer (CEO).

Question \#2: Only $12 \%$ of the respondents performed GHG emission inventories, whereas $80 \%$ of the respondents performed annual projections of GHG emissions. Of the organizations that did not perform GHG emissions inventories, only $20 \%$ of the organizations intended to perform inventories in the near future. Annual projected GHG emission inventories are essential to the search for sustainability and to the development of corporate strategies to mitigate and adapt to climate change $[12,14,33,34]$. Considering the urgency to reduce GHG emissions that was established by international guidelines [2-4,11,22,23,29], the minimal degree of commitment to quantifying and mitigating GHG emissions as revealed by the survey is problematic compared with similar studies $[14,44]$. This finding indicates a strong global trend towards the incorporation of sustainability and climate change into the strategies of organizations. These results indicate a lack of alignment and adherence to Brazilian climate change policy by these companies. However, they also explain why emissions from electricity generation in Brazil increased from 20\% (2005) to 39\% (2010). GHG emissions can be reported by an organization in several ways. To ensure a clear position relative to the market and Brazilian climate change policy, an organization must use metrics and reliability calculations based on internationally accepted standards. Guidelines for categorizing relevant emission sources and metrics for quantifying GHG emissions are available on the web pages of various international organizations (e.g., World Resources Institute (WRI), World Business Council for Sustainable Development (WBCSD), and Greenhouse Gas Protocol (GGP)).

Question \#3: Although $99 \%$ of the organizations answered the question regarding the fiscal/tax incentives for reducing GHG emissions, only $25 \%$ of the organizations were familiar with these incentives. Sixty-five percent of these groups reported knowledge of the differentiated financial lines available in Brazil (BNDES, CEF, BB) [47], 45\% of the groups were familiar with tax reduction programs (ITBI, ISS, IPTU, IPI e ICMS) [48], and 50\% of the groups were familiar with the green 
market (carbon credit market) eligibility criteria. Eighty-eight percent of the organizations that were unfamiliar with the available fiscal benefits expressed an interest in learning about them. Their lack of knowledge about the fiscal incentives for reducing GHG emissions in Brazil is problematic as these incentives are important mechanisms for establishing technically and financially feasible solutions that may contribute to a low-carbon economy. These mechanisms create the necessary financial conditions for organizations to respond and adapt to the risks and threats of climate change [27,35]. They also guide investment alternatives to priority areas, which ensure that the management and objectives of an organization are integrated with the goals of the Brazilian climate policy and the guidelines recommended by international organizations. [11,12,14,23,33,44]. However, the lack of attention given to these benefits suggests either a corporate culture that lacks knowledge of the potential advantages via improved branding and competitive positioning or an inefficient concession mechanism.

Question \#4: Only $37 \%$ of the participating organizations responded regarding their knowledge about the carbon market; $41 \%$ of these groups were aware of the carbon market. Of the organizations that were aware of the carbon market, $71 \%$ had plans to develop a CDM project, $27 \%$ had on-going CDM projects and 14\% already possessed carbon credit certificates. For the organizations unaware of the carbon market, $68 \%$ demonstrated an interest in learning about it. The global carbon market assists with projects aimed at reducing the GHG emissions of different industries [11,24,49]. Brazil has the third-highest number of CDM projects for any country [49]; this result reflects an incipient action towards international goals. The development of CDM projects facilitates the development of a low-carbon economy by generating carbon credits or a culture and knowledge for managing the GHG emissions of an organization $[11,14,33,34,44,49]$.

Question \#5: A small percentage of the organizations-29\%-responded to this question, which inquires about any periodical risk/opportunity analyses performed with regard to climate change and sustainability. Only $28 \%$ of the participants responded positively. The performance of risk and opportunity analyses related to climate change and sustainability exhibits different short-, medium- and long-term impacts $[27,44]$. These analyses contribute to the planning and image of an organization in the market, provide information to the government about emerging public incentive policies, expose an organization's vulnerabilities to risks and threats and stimulate the development of strategies for adapting to climate change $[27,31,44]$. These analyses also contribute to organizational learning, as comprehension of the local specificities strengthens the organizational capacity to anticipate and minimize future risks $[12,14,44]$. However, these results require effective stakeholder involvement when addressing global and local issues and searching for innovative solutions using a scientific knowledge of probabilities and reactive thresholds rather than previous statistical data. Potential risks and opportunities must be identified to comprehend current and future GHG emissions in the context of a society and economy that are constrained by current and future carbon restrictions. The lack of habitual risk and opportunity analyses of climate change and sustainability threats suggests that these issues have not been incorporated into the business strategies of these companies, which exposes them to economic, physical and regulatory risks that can negatively impact their image. A Carbon [50] Disclosure Capture study gathered opinions and intentions from 379 organizations in different industries [14], which represented the interests of 655 investors, each of which had amassed wealth in the amount of US\$ 78 trillion. The study results indicated that $81 \%$ of the organizations were aware of the physical risks associated with climate change in their business environments. Specifically, $83 \%$ of 
the organizations were aware of the regulatory risks and $63 \%$ of the organizations were aware of risks associated with reputation and consumer behavior. The survey also revealed that $64 \%$ of the respondents were aware of the opportunities associated with the physical consequences of climate change, $80 \%$ of the respondents were aware of the regulatory consequences of climate change and $68 \%$ of the respondents were aware of the consequences of climate change associated with reputation and consumer behavior.

Question \#6: This question garnered a high degree of participation (98\%), with $91 \%$ of the respondents perceiving sustainability as a business opportunity. Although it is commendable that the majority of organizations view sustainability as an effective business opportunity (and not solely as an additional cost), this finding is only the first step towards the development of new values, products, processes, relationships and markets. Considering sustainability in the business world prompts an extensive learning cycle, in which nontraditional questions with nontrivial answers establish new challenges and game rules [12,39]. During this extensive learning cycle, the following questions are highlighted: What products will be successful in a GHG-emission-restricted market? How can research, development and innovation be directed to address the challenging demands of sustainability and climate change? How can stakeholders be clearly and transparently informed? Which creative and conscious criteria signal the selection of low-impact raw materials and renewable energy alternatives? How can an organization contribute to the re-evaluation of society's consumptive behaviors via green products and technologies?

Question \#7: Amongst the respondents that answered this question, which inquires whether an organization perceives sustainability as a competitive differential, $95 \%$ of the respondents answered positively. In the unfolding questions, $79 \%$ of the respondents considered sustainability strategies to reduce fixed costs; $37 \%$ of the respondents considered stakeholder and shareholder involvement; $66 \%$ of the respondents considered sustainability to be strategic and operationally efficient; $66 \%$ of the respondents considered the preferences of consumers, suppliers or investors; $52 \%$ of the respondents identified an opportunity to develop new markets; $55 \%$ of the respondents considered sustainability to be a pioneering and anticipation action; $70 \%$ of the respondents considered sustainability to be a strategy that differentiated the organization, its products and services; and $27 \%$ of the respondents identified an opportunity for brand improvement. The understanding that sustainability may be a competitive differential encourages the adoption of green branding and the creation and exploitation of emerging opportunities [14,16-18,20,33]. While searching for this differential, an organization must identify the best practices for and solutions to climate change and sustainability to evaluate its exposure to GHG emission restrictions and comprehend how these factors affect its market position. Organizations must consider their GHG emissions profile relative to their market peers and other industries, potentially relevant future regulatory developments, the cost trends of raw materials and potential changes in customer preferences [12,27,51]. The declaration by the majority of companies (91\%) that sustainability is a business opportunity and a competitive differential indicates a consensus on the need to prioritize a sustainability agenda.

Question \#8: All respondents identified acceptable sustainability practices in their organizations. Eighty percent of the respondents reported selective garbage collection; 65\% of the respondents reported sewage and wastewater treatment; $29 \%$ of the respondents reported the generation and/or utilization of renewable energy; $70 \%$ of the respondents reported the recycling and reuse of residues; 
$42 \%$ of the respondents reported energy efficiency and raw material optimization; $51 \%$ of the respondents reported environmental education; $33 \%$ of the respondents reported rainwater collection; $20 \%$ of the respondents reported reverse logistics for their products; $14 \%$ of the respondents reported the neutralization and/or compensation of carbon emissions; $50 \%$ of the respondents reported social development programs; $36 \%$ of the respondents reported cultural development programs; $51 \%$ of the respondents reported professional well-being programs and $2 \%$ of the respondents reported other reasons (options not listed in the questionnaire). Based on the studies cited in this paper, the listed activities reflect a set of challenges that climate change and sustainability have imposed on the basic operations of an organization, which indicates the best business practices and identifies the degree of commitment and integration of these issues into daily actions. These activities also contribute to a stakeholder's awareness of and involvement in the well-being of the local community, the preservation of the ecosystem's resources and the sustainability of the organization $[12,52,53]$.

Question \#9: Only 25 (29\%) of the 86 entities surveyed answered this question, which inquires about participation in any program/competition that awards sustainability. Of the four organizations that responded positively, each organization declared that it had received an award. Participation in awards programs is considered to be a healthy and motivation-inducing practice. Participation stimulates stakeholder involvement in an organizations' challenges and achievements; facilitates access to the multi-discipline evaluation of their sustainability and climate change activities, actions, products and processes; increases an organization's exposure to the judgment and criticism of external evaluators from different areas and provides access to strategic financial benefits and the conquest of market leadership awards.

Question \#10: Only $15 \%$ of the respondents who answered this question reported that they received sustainability and energy efficiency certificates. Sustainability and energy efficiency certificates contribute to the credibility and competitive position of an organization in the green market [12,52,54]. The attainment of these certificates informs the market that an organization satisfies a set of national and international norms and guidelines that advocate an efficient, reliable and clean use of raw materials, residues, products, and processes. These certificates facilitate market negotiations and facilitate the transfer of knowledge and technologies [52].

Question \#11: Only 21\% of the respondents publicize their actions on sustainability and climate change via different communication tools. None of the respondents selected the options "Carbon Disclosure Project" report or "corporate social responsibility report". The dissemination of knowledge and the publication of sustainability and GHG emission reports contribute to the participatory, communicative and transparent relationship between stakeholders and shareholders [14,55]. These reports help organizations to establish actions, goals, metrics, indicators and management models for sustainability and climate change, which improves the efficacy of their operations $[33,34,44]$. The reports collaborate to improve the comprehension of an organization's strategic development and planning and provide valuable information that is accessible and comparable, which helps stakeholders to make decisions [12,55]. For these reasons, the impact of an organization's actions and strategies for mitigating and adapting to climate change in the environment, economy and society should be publicized. 


\subsection{Sectoral Analysis and Degree of Commitment}

The degree of commitment to emissions restrictions exhibited by the participating organizations with regard to the international guidelines that define sustainable actions and strategies for mitigating and adapting to climate change, which were summarized by the 14 critical actions listed in Section 3, was evaluated based on the proposed indicator of commitment (IC) and metrics [28].

\subsubsection{Proposed $C I$ and Metrics}

The CI (commitment index), which is defined by Equation (1), counts the total number of [YES] answers (Table 1) and questions (Table 2) selected by the respondents.

$$
C I(\%)=\frac{1}{2 N}\left(\frac{1}{D_{Y}} \sum_{n=1}^{n=18} Y_{n}+\frac{1}{D_{M}} \sum_{m=1}^{m=48} M_{m}\right) \times 100
$$

where $N$ is the total number of entities that participated in the survey, $D_{Y}$ is the total number of [YES] answers required for the maximum score, $D_{M}$ is the total number of questions required for the maximum score, $Y_{N}$ is the score for each [YES] answer, $M_{M}$ is the score for each multiple-choice question and $n$ and $m$ represent the indices of the summation operator (which counts the [YES] answers for the 18 [YES] or [NO] and 48 multiple-choice questions in the questionnaire).

Due to the structure of the questionnaire, which redirects respondents to the [YES] or [NO] responses to the 11 primary questions (Table 1), the metrics calculate the total number of selected positive options. This score establishes the adherence of the participating organization to the critical questions on which the questionnaire is based. Therefore, to prevent duplicate scoring, 11 of 18 [YES] alternatives define the maximum score for any respondent. Similarly, a total of 23 of 48 possible multiple-choice answers (refer to Table 2) is the maximum score for these questions, which adapts the answer options to the profile of each economic sector (i.e., it is unreasonable to ask a company with low electrical usage if it employs renewable energy generation when the investment cost/benefit is unattractive; it is also unreasonable to ask a service provider about wastewater treatment and/or reverse logistics if manufacturing is not performed). Once these restrictions on the $C I$ are introduced to the proposed model, the parameters of the [YES] or [NO] and multiple-choice questions possess the following values: $D_{Y}=11$ and $D_{M}=23$. In other words, the proposed $C I$ formulation incorporates some sort of weighting system to compensate for sectoral and size differences amongst respondent categories allowing this composite $C I$ approach to capture what a quick perusal of the responses over all 18 action categories readily reveals.

Thus, Equation (1) can be used to calculate the degree of commitment to emissions restrictions $C I$ for the following three situations: (i) each participating organization $(N=1)$; (ii) each economic sector to which the organizations belong ( $N$ denotes the total of all participants that belong to a certain sector) and (iii) the entire sample of 86 participants $(N=86)$.

\subsubsection{Statistics}

Figure 1 summarizes the performed statistical analyses. Although the sample mean value (0.432) of the commitment index (CI) for emissions restrictions is close to the median value (0.409) — which 
suggests a symmetric distribution-the Chi-square hypothesis test $\left(x^{2}\right)$ performed at a confidence level of $99 \%$ (significance level of 1\%) confirms that the actual data exhibits a Beta distribution with the parameters $\alpha=2.67$ and $\beta=3.52$. This distribution enables the definition of distinct groupings in terms of the corresponding percentiles $(25 \%, 50 \%, 75 \%$ and $100 \%)$ of the sample, i.e.,: EXCELLENT: $C I \geq 74 \%$ for organizations that responded [YES] in the $74 \%-100 \%$ assertiveness range; GOOD: 50\% $<C I<74 \%$; AVERAGE (around average): $33 \% \leq C I \leq 50 \%$ and POOR: $C I<33 \%$ for data below a minimum of $33 \%$ adherence to the critical questions associated with emissions restrictions. A database based on the individual value of the $C I(\%)$ calculated for each participating organisation $(N=1)$ was created for the statistical analyses.

Figure 1. Statistical framework that supports the categorization of classes of CIs.
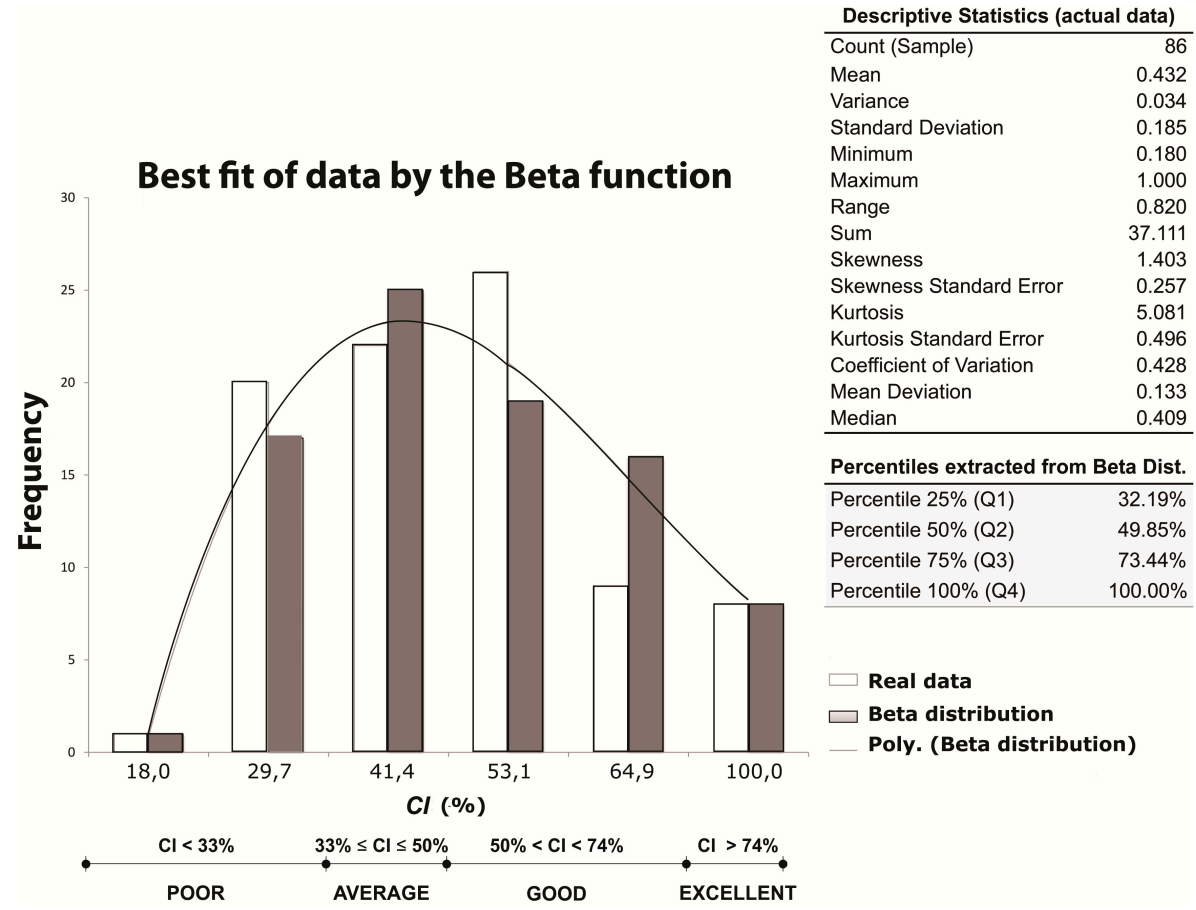

The proposed metric, as shown in Equation (1), was used as a reference to calculate the degree of commitment to emissions restrictions ( $C I$ index) for the entire sample $(N=86)$ based on the data in Tables 1 and 2, which summarise the respondents' answers to each question. The degree of commitment was recalculated for each class according to the 5 economic sectors previously mentioned in this study; i.e., manufacturing ( $N=32$ companies); commerce ( $N=28$ companies); public organizations ( $N=9$ companies); education and research ( $N=7$ companies) and tourism, entertainment and culture ( $N=10$ companies). By calculating each of these segments of the total sample and counting the [YES] (shown in Table 1) and multiple-choice answers (shown in Table 2), the degree of commitment $C I$ was calculated for each economic sector.

The results are shown on the left side of Table 3, which compares the specificities for the different economic sectors and classifies the participants according to the adopted Excellent-Good-Average-Poor scale. 
Table 3. Degree of commitment classified by sector and total GHG emissions ( $\left.\mathrm{t} \mathrm{CO}_{2} \mathrm{eq}\right)$.

\begin{tabular}{|c|c|c|c|c|c|c|c|c|c|c|}
\hline \multirow{2}{*}{$\begin{array}{l}\text { Energy consumers } \\
\text { classified by type of } \\
\text { industry (sector) }\end{array}$} & \multicolumn{6}{|c|}{ Indicator of Commitment to international Guides (IC) } & \multicolumn{2}{|c|}{$\begin{array}{c}\text { Energy } \\
\text { consuming unit }\end{array}$} & \multicolumn{2}{|c|}{$\begin{array}{c}\text { (*) Average annual } \\
\text { equivalent GHG emission }\end{array}$} \\
\hline & $\begin{array}{c}\text { MEAN } \\
(\%)\end{array}$ & TOTAL & EXCELLENT & GOOD & AVERAGE & POOR & $\begin{array}{l}\text { by Sector } \\
\text { (MWh) }\end{array}$ & $\begin{array}{c}\text { by } \\
\text { consuming } \\
\text { unit (MWh) }\end{array}$ & $\begin{array}{c}\text { by } \\
\text { industry } \\
\left.\mathrm{CO}_{2} \mathrm{eq}\right)\end{array}$ & $\begin{array}{l}\text { by consuming } \\
\text { unit }\left(\mathrm{tCO}_{2} \mathrm{eq}\right)\end{array}$ \\
\hline Education \& Research & 46.9 & 7 & 1 & 1 & 2 & 3 & 102,482 & $14,640.3$ & 10,453 & 1493.3 \\
\hline $\begin{array}{l}\text { Manufacturing } \\
\text { (Industry) }\end{array}$ & 45.2 & 32 & 2 & 7 & 17 & 6 & 167,368 & $5,230.3$ & 17,071 & 533,5 \\
\hline Public Organizations & 43.5 & 9 & 1 & 1 & 4 & 3 & 235,298 & $26,144.2$ & 24,000 & 2666.7 \\
\hline Commerce & 43.2 & 28 & 1 & 5 & 17 & 5 & 97,505 & 3482.3 & 9945 & 3552 \\
\hline $\begin{array}{c}\text { Entertainment/ } \\
\text { Culture/Tourism }\end{array}$ & 34.6 & 10 & 1 & 0 & 2 & 7 & 25,802 & 2580.2 & 2632 & 2632 \\
\hline All Economic Sectors & 43.2 & 86 & 6 & 14 & 42 & 24 & 628,445 & 7307.5 & 64,101 & 7454 \\
\hline
\end{tabular}

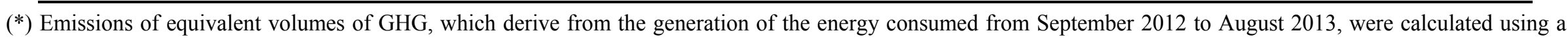
conversion factor (annual average) of $0.102 \mathrm{tCO}_{2} \mathrm{eq} / \mathrm{MWh}$. The Brazilian Ministry of Science, Technology and Innovation publishes the applicable conversion factor each month. Source: [56]. 


\subsubsection{Assessment of the Level of Carbon Dioxide Emissions and Discussion}

This study also considered the electrical energy consumption of each participating organization (aggregated by sector), which can be translated into the average annual carbon dioxide emissions equivalent $\left(\mathrm{tCO}_{2} \mathrm{eq}\right)$. To provide more information on this analysis, these data were included in Table 3 , which enabled the degree of commitment $C I$ to be compared to the annual average electricity consumption (MWh) and the total GHG emissions $\left(\mathrm{tCO}_{2} \mathrm{eq}\right)$, which were based on the electrical consumption by the survey participants. The global analysis of the study results are summarized as follows:

- The descriptive statistics for the entire sample $(N=86)$ revealed the following average degree of commitment: $\overline{C I_{\text {med }}}=0.432$ (standard deviation: $\sigma=0.185$ ). Therefore, the entire sample fell into the Average quartile, i.e., $(33 \% \leq C I<50 \%)$. The same results apply to each of the sectors, with all samples falling into the Average quartile.

- The average annual GHG emissions from the generation of the energy consumed by the survey participants indicated that Public Organizations emitted 9.1-fold more GHGs than the Entertainment, Culture and Tourism sector, 2.3-fold more GHGs than the Education \& Research sector and 1.4-fold more GHGs than the Manufacturing industry. As the majority of participating organizations (88.4\%) do not inventory their GHG emissions and none created "Carbon Disclosure Project" reports (sub question $b$ of question \#11), a comparative analysis between the "Carbon Footprint" [42] of each sector and the degree of commitment to emissions restrictions CI was not feasible.

- Regarding renewable energy usage as an efficient GHG emission reduction strategy (sub question $c$ of question \#8), the sector that consumed the second-highest amount of electricity (manufacturing) was the least committed to using alternative energy (16\%). The next highest consumers included Commerce (29\%), Public Organizations (44\%), Education \& Research (43\%) and Entertainment, Culture \& Tourism (50\%).

- Actions to increase energy efficiency (sub question $e$ of question \#8) were led by Education \& Research (57\%), followed by Commerce (43\%), Manufacturing (41\%), Entertainment, Culture \& Tourism (40\%) and Public Organizations (33\%).

- Public Organizations answered the most positively with regard to the neutralization or compensation for carbon emissions (22\%, sub question $i$ of question \#8), followed by Manufacturing (19\%), Education \& Research (14\%); Commerce (7\%) and Entertainment, Culture \& Tourism (10\%).

- Sustainability and energy efficiency certificates (question \#10) were most pursued by Public Organizations (29\%), followed by Commerce (28\%), Manufacturing (13\%) and Education \& Research (11\%); however, they were not a priority for the Entertainment, Culture \& Tourism sector. The international LEED building mark of conformity and certification that supports an environmental orientation system, which is considered by organizations in 143 countries to be a strategy for encouraging projects, constructions and building operations that focus on sustainability, was only prioritized by $3 \%$ of the respondents in Manufacturing and $7 \%$ of the respondents in Commerce. The certification required to obtain the PROCEL Edifica Certificate was also of minimal interest to the respondents; this certificate had been obtained by only $3 \%$ of 
the participants in Manufacturing. The Solar certificate and its mark of conformity were only obtained by $14 \%$ of the Education and Research participants and $7 \%$ of the Commerce participants.

These analytical results revealed that only six of the 86 participating organizations achieved an Excellent degree of commitment to emissions restrictions (two Manufacturing companies that specifically handle mineral extraction and commercialization; one wood commercialization company; one Public Organisation in the area of urban public transportation; one participant in Education and Research, which is prominent in this field, and one participant in Entertainment, Culture and Tourism). The remainder of the results are as follows: 14 organizations scored a Good degree of commitment, 42 organizations scored an Average degree of commitment and 24 organizations scored a Poor degree of commitment. The recent CGS (2013) study indicated that large global organizations lead the commitment to sustainability. The CGS study emphasized that the primary barriers to developing successful sustainability strategies by small- and medium-size organizations include a lack of investments and the specialized knowledge about these critical issues.

The study utility supplies 31 municipalities in the State of Rio de Janeiro (the city of Rio de Janeiro, the Baixada Fluminense - part of the metropolitan area — and the Paraiba River Valley). Regardless of the sample size, which was conveniently classified by the consumer unit class, the utility serves approximately 4.1 million consumers, which represents $68 \%$ of the population and $66 \%$ of the gross internal product for the State of Rio de Janeiro. The electricity power company adopted a new initiative in 2012, which is committed to the Global Pact and included sustainability as one of the priorities of its strategic plan. As demonstrated by this study, this initiative has not yet affected its customers. Although this company penetrates all segments of society in the State of Rio de Janeiro, institutional or governmental policies that support mechanisms for inducing a proactive culture, in which customers are motivated to reduce the GHG emissions of their energy usage, are non-existent. By affirming this belief, the utility company strategically positions itself to imprint institutional action to rethink productive activities in the context of sustainability and to adopt a more conscious posture regarding the risks and threats of climate change.

\section{Conclusions and Policy Implications}

Even though some knowledge about the response of firms in advanced economies to climate change are described in the literature [57-59], very little is known about organizations in developing and emerging economies that, certainly, also have a huge and growing impact on the environment. The considerations that were obtained from the survey results associated with this complex subject were obtained from the survey results were detailed for a representative sample of high-consuming customers (classified by economic sector) of an electricity power company. With the exception of a few outliers, the average degree of commitment $\left(\overline{C I_{\text {med }}}=0.432\right)$ for the participants was ranked Average, which indicates the incipience of proactive GHG strategies (less than $7 \%$ of the participants fell within the Excellent category) in response to the guidelines established by the Brazilian Climate Change Policy. There are very few firms who've done much. And the "average" degree of engagement seems to be very low and most likely has little effect on the overall GHG emissions.

The survey reveals a low commitment to the guidelines of the Brazilian Climate Change Policy. Brazil has not enacted specific regulations to mitigate the GHG emissions associated with the 
generation of electricity; this finding is certainly a matter of concern due to the size and the regional influence of the country to the global climate change. Therefore, the survey indicates the need for a proactive attitude towards the mitigation and adaptation to climate change in the context of sustainable development strategies. Specifically, the survey indicates the need for realignment with new methods that address the risks, threats, uncertainties and complexities of the undesired impacts of climate change. Although Brazil lacks specific legislation to isolate the production of electricity from its negative impact on the environment, the recent (2012) initiative of the regulatory agency is encouraging. Aneel (Brazilian Electricity Regulatory Agency) Resolutions 414 and 415 stimulate solar electricity generation through an $80 \%$ rate discount (until 2017) for the use of the solar electricity distribution and transmission systems (the discount will be reduced to $50 \%$ after 2017).

Although this impact will occur on different levels and time scales, everyone, regardless of his/her degree of awareness, will be affected by the global climate change phenomenon. Only a global effort with unrestrictive adherence by various nations will enable a GHG emission control plan to transition from the current conformity to non-polluting policies with conscious markets, manufacturing modes and relationships. The competitive advantages of these organizations must be globally reorganized with regard to current environmental issues and as a safeguard to climate change mitigation and adaptation. As recently mentioned in the Global Corporate Sustainability Report, which was published by the United Nations [46], although organizations declare a desire to incorporate actions that prioritize sustainability, mitigation and adaption to climate change in their corporate strategies, these initiatives only produce long-term results.

The measured low commitment to emissions restrictions of large users of electricity certainly calls for further attention to the more general context in which firms act to reduce their GHG footprints. Individual firms can only go so far in cutting emissions via efficiency measures or technological change. Power companies, on the other hand can act more centrally to lessen dependence on coal and fossil fuels more generally, even without fostering intra-firm change. In the case of Brazil, moreover, the contribution of hydropower and other renewables is already unusually high so further increments of improvement may have diminishing effect. The transport sector is surely a prime target for further national/global gain given a relatively slow pace of hybrid adoption and continuing reliance on gasoline and ethanol, not to forget the complexities associated with the latter when land use, food production and the net-negative energy effects have to be taken into account. The incisive reduction in GHG emissions proposed by the 2013 Report of the IPCC is linked to a review of the historical responsibilities of nations for different degrees of development. Each agent, regardless of size, belief or economic and social activities, is responsible for exploring opportunities to develop strategies towards development and participation in the global environment.

\section{Acknowledgments}

To the Brazilian Regulator ANEEL, for the opportunity to participate in its Regulated R\&D Program (Project Light/ANEEL Project 80/2011); to the UE, for the funding of the FP7 project "Bottom-up Climate Adaptation Strategies towards the Sustainable Europe" (Grant Agreement 308337); to CAPES/Brazil and to the Fundação para a Ciência e Tecnologia (scholarship 
SFRH/BPD/65977/2009) for the financial support and to the Science Without Borders High Education Programme of the Brazilian government, for financing the post-doctoral program of the first author.

\section{Author Contributions}

Even though all authors have contributed to the overall development of the paper and analysis/discussion of the results, the first two authors were responsible for designing and writing the article. The third author reviewed the analysis for data consistency while the last co-authors concentrated on data processing and on filtering the firms to meet the pre-established eligibility compliance criteria for participating in the survey.

\section{Conflicts of Interest}

The authors declare no conflict of interest.

\section{References and Notes}

1. Meadows, D.; Randers, J.; Meadows, D. Limits to Growth: The 30-year Update; Chelsea Green Publishing Company: Vermont, VT, USA, 2004; pp. 81-96.

2. Intergovernmental Panel on Climate Change (IPCC). Climate Change 2007: An Assessment of the Intergovernmental Panel on Climate Change; Intergovernmental Panel on Climate Change (IPCC): Geneva, Switzerland, 2007; pp. 26-52.

3. Intergovernmental Panel on Climate Change (IPCC). Managing the Risks of Extreme Events and Disasters to Advance Climate Change Adaptation; Intergovernmental Panel on Climate Change: New York, NY, USA, 2012; pp. 25-542.

4. Intergovernmental Panel on Climate Change (IPCC). Climate change 2013: The physical science basis. In Working Group I Contribution to the Fifth Assessment Report of the Intergovernmental Panel on Climate Change; Stocker, T.F., Qin, D., Plattner, G.-K., Tignor, M.M.B., Allen, S.K., Böschung, J., Eds.; Cambridge University Press: New York, NY, USA, 2013; pp. 3-115.

5. United Nations (UN). Report of the United Nations Conference on the Human Environment; United Nations: Stockholm, Sweden, 1972; pp. 3-76.

6. Brundtland, G.H. Report of the World Commission on Environment and Development: Our Common Future; United Nations: New York, NY, USA, 1987; pp. 41-46.

7. Houghton, J.T.; Jenkins, G.J.; Ephraums, J.J. Climate Change: The Ipcc Scientific Assessment; Cambridge University Press: Cambridge, UK, 1990.

8. United Nation (UN). Conference on Sustainable Report of the United Nations Conference on Sustainable Development; United Nations: New York, NY, USA, 2012; pp. 1-126.

9. European Commission. Regions 2020-The Climate Change Challenge for European Regions; European Commission-Directorate General Regional Policy: Brussels, Belgium, 2009; pp. 10-22.

10. German Advisory Council on Global Change (WBGU). World in transition: A social contract for sustainability. In Summary for Policy-Makers; Deutsche Nationalbibliothek: Berlin, Germany, 2011; pp. 1-25. 
11. World Bank (WB). $4{ }^{\circ} \mathrm{C}$ the Turn Down the Heat: Why a $4{ }^{\circ} \mathrm{C}$ Warmer World Must be Avoided; International Bank for Reconstruction and Development: Washington, DC, USA, 2012.

12. Hoffman, A.J. Getting Ahead of the Curve: Corporate Strategies that Address Climate Change; The Pew Charitable Trusts: Washington, DC, USA, 2006; pp. 5-128.

13. Agrawala, S.; Fankhauser, S. Economic Aspects of Adaptation to Climate Change: Costs, Benefits Andpolicy Instruments; The Organisation for Economic Co-operation and Development (OECD): Paris, France, 2008; pp. 19-127.

14. Carbon Disclosure Project (CDP). Business Resilience in an Uncertain, Resource-Constrained World: ${ }^{\circ} \mathrm{C}$ dp Global 500 Climate Change Report 2012; Carbon Disclosure Project: London, UK, 2012; pp. 40-60.

15. Cleveland, M.; Kalamas, M.; Lorache, M. Consumer behaviour; green marketing; social responsibility. J. Consum. Mark. 2005, 22, 198-212.

16. Dahl, R. Green washing: Do you know what you're buying? Environ. Health Perspect. 2010, 118, 246-252.

17. First, I.; Khetriwal, D.S. Exploring the relationship between environmental orientation and brand value: Is there fire or only smoke? Bus. Strateg. Environ. 2010, 19, 90-103.

18. Junquera, B.; Brío, J.Á.d.; Fernández, E. Clients' involvement in environmental issues and organizational performance in businesses: An empirical analysis. J. Clean. Prod. 2012, 37, 288-298.

19. Hoffman, A.J.; Woody, J.G. Climate Change: What's Your Business Strategy? Harvard Business Review Press: Boston, MA, USA, 2008.

20. Weinhofer, G.; Hoffmann, V.H. Mitigating climate change-How do corporate strategies differ? Bus. Strateg. Environ. 2010, 19, 77-89.

21. Sprengel, D.C.; Busch, T. Stakeholder engagement and environmental strategy-The case of climate change. Bus. Strateg. Environ. 2011, 20, 351-364.

22. United Nations (UN). Report of the United Nations Conference on Environment and Development; United Nations: New York, NY, USA, 1992; pp. 3-351.

23. United Nations (UN). Report of the United Nations Conference on Sustainable Development; United Nations: New York, NY, USA, 2012; pp. 1-126.

24. World Bank (WB). State and Trends of the Carbon Market; World Bank: Washington, DC, USA, 2010; pp. 95-138.

25. Ministério de Minas e Energia (MME). Balanço Energético Nacional. Ano base 2012; Ministério de Minas e Energia do Brasil: Brasília, Brasil, 2013; pp. 15-284. (In Portuguese)

26. Published Decree 7390/2010, Art. 11. Available online: http://www.planalto.gov.br/ccivil_03/ _Ato2007-2010/2010/Decreto/D7390.htm (accessed on 20 August 2014).

27. Empresa de Pesquisa Energética (EPE). Avaliable online: https://ben.epe.gov.br/downloads/ S\%C3\%ADntese\%20do\%20Relatório\%20Final_2013_Web.pdf (accessed on 20August 2014).

28. By force of Decree 7390/2010 of 09/12/2010, the estimation of Brazilian GHG emissions for 2020, as listed in art. 12 of Law 12187/2009, is 3236 million tons $\mathrm{CO}_{2}$ eq, with 868 million tons $\mathrm{CO}_{2}$ eq attributed to the energy sector.

29. Instituto de Pesquisa Econômica Aplicada (IPEA). Mudança Do Clima No Brasil: Aspectos Econômicos, Sociais E Regulatórios; Instituto de Pesquisa Econômica Aplicada: Brasilia, Brazil, 2011; pp. 10-428. 
30. Michaelowa, A.; Michaelowa, K. Climate business for poverty reduction? The role of the world bank. Comp. Int. Stud. 2011, 6, 259-286.

31. Santos, F.D. Humans on Earth-From Origins to Possible Futures; Springer: New York, NY, USA, 2012.

32. European Environment Agency (EEA). Adaptation in Europe: Addressing Risks and Opportunities from Climate Change in the Context of Socio-Economic Developments; EEA: Luxembourg, 2013; pp. 12-61.

33. Mills, E. A global review of insurance industry responses to climate change. Geneva Pap. 2009, 34, 323-359.

34. Carbon Disclosure Project (CDP). Brazil Climate Change Report: From Disclosure to Action; Carbon Disclosure Project: London, UK, 2012; pp. 1-52.

35. Carbon Disclosure Projet (CDP). Carbon Reductions Generate Positive ROI-Carbon Action Report 2012: On Behalf of 92 Investors with Assets of \$10 Trillion; Carbon Disclosure Projet: London, UK, 2012; pp. 2-9.

36. United Nations (UN). Kyoto Protocol; United Nations: New York, NY, USA, 1998; pp. 1-20.

37. Dyllick, T.; Hockerts, K. Beyond the business case corporate sustainability. Bus. Strateg. Environ. 2002, 11, 130-141.

38. Lee, S.-Y. Corporate carbon strategies in responding to climate change. Bus. Strateg. Environ. 2012, 21, 33-48.

39. Hoffman, A.J. Climate change strategy: The business logic behind voluntary greenhouse gas reductions. Calif. Manag. Rev. 2005, 47, 21-46.

40. Kolk, A.; Pinkse, J. Business responses to climate change: Identifying emergent strategies. Calif. Manag. Rev. 2005, 47, 6-20.

41. Hoffman, A.J. Carbon Strategies: How Leading Companies are Reducing Their Climate Change Footprint; University of Michigan Press: Ann Arbor, MI, USA, 2007.

42. High-consuming customers of electricity power companies are designated by the Brazilian regulating agency. Aneel 414:2010 resolution classifies the consumption units into three categories: (i) blue hourly rate: $69 \mathrm{kV}$, (ii) green or blue hourly rate: less than $69 \mathrm{kV}$ with a demand higher than or equal to $300 \mathrm{~kW}$, and (iii) blue or green hourly rate: less than $69 \mathrm{~kW}$ with a demand higher than $300 \mathrm{~kW}$ (Aneel, 2012).

43. Jeswani, H.K.; Wehrmeyer, W.; Mulugetta, Y. How warm is the corporate response to climate change? Evidence from pakistan and the UK. Bus. Strateg. Environ. 2008, 14, 46-60.

44. Agência Nacional de Energia Elétrica (ANEEL). Manual do Programa de Pesquisa e Desenvolvimento Tecnológico do Setor de Energia Elétrica; ANEEL: Brasilia, Brazil, 2012; p. 61.

45. Créhalet, E. Climate Change Adaptation: Underwriting Risks for (Re)insurers; Kepler Cheuvreux-Carbon Disclosure Project: London, UK, 2013; pp. 43-49.

46. Costa, H.; Baltazar, A. Índice acge 2011 responsabilidade climática en portugal; Euronatura: Liboa, Portugal, 2011; pp. 1-80. (In Galician)

47. ITBI: Tax on real estate transmission; ISS: Tax on services; IPTU: Real estate property tax; IPI: Federal value-added tax on industrialised products; ICMS: State value-added tax on sales and services. 
48. For reasons of confidentiality, only aggregated data are reported. The individual $C I s$ for each organisation are unpublished.

49. United Nations (UN). Global Corporate Sustainability Report; United Nations: New York, NY, USA, 2013; pp. 3-24.

50. The "Carbon Footprint" calculates the direct, indirect, fixed and variable GHG emissions of the organisations.

51. Neto, A.L.N.d.M.; Frondizi, I.M.d.R.L.; Amaral, P.C.; Roxo, L.C.F.; Machado, B.V.Z.; Rymer, J.V.; Messer, P.; Brajterman, O.; Mattos, T.d.M.; Frondizi, F.d.R.L.; et al. Strengthening of the Brazilian Carbon Market's Institutions and Infrastructure: Levantamento de Oportunidades Concretas de Projetos de Baixo Carbono No Brasil; World Bank: Washington, DC, USA, 2010; pp. 6-242.

52. Davies, A.R.; Mullin, S.J. Greening the economy: Interrogating sustainability innovations beyond the mainstream. J. Econ. Geogr. 2011, 11, 793-816.

53. International Organization for Standardizatio (ISO). Action on climate change. ISO Focus 2008, $5,1-48$.

54. European Public Real Estate Association (EPRA). Best Practices Recommendations on Sustainability Reporting; European Public Real Estate Association: Brussels, Belgium, 2011; pp. 26-35.

55. Environment and Human Health (EHHI). LEED Certification: Where Energy Efficiency Collides with Human Health; Environment and Human Health: North Haven, ME, USA, 2010; pp. 6-64.

56. The Brazilian Ministry of Science, Technology and Innovation of Brazil. Arquivos dos fatores de emissão de $\mathrm{CO}_{2}$ eq. Avaliable online: http://www.mct.gov.br/index.php/content/view/ 321144.html\#ancora (accessed on 2 October 2013).

57. Global Reporting Initiative (GRI). G4 Sustainability Reporting Guidelines; Global Reporting Initiative (GRI): Amsterdam, NY, USA, 2013; pp. 3-94.

58. Pinkse, J.; Kolk, A. Multinational enterprises and climate change: Exploring institutional failures and embeddedness. J. Int. Bus. Stud. 2012, 43, 332-341.

59. Kolk, A. Trajectories of sustainability reporting by mncs. J. World Bus. 2010, 45, 367-374.

(C) 2014 by the authors; licensee MDPI, Basel, Switzerland. This article is an open access article distributed under the terms and conditions of the Creative Commons Attribution license (http://creativecommons.org/licenses/by/3.0/). 